\title{
A Cross-Organization Collaboration Framework of Nuclear Power Plant Accidents Emergency Management in Off-Site Area: A Case Study from S City
}

\author{
Chunfei Deng, Pan Tang \\ School of Public Management/Emergency Management, Research Center of Emergency Management, Jinan University, \\ Guangzhou, China \\ Email: dengchunfeijnu@gmail.com
}

How to cite this paper: Deng, C. F., \& Tang, P. (2017). A Cross-Organization Collaboration Framework of Nuclear Power Plant Accidents Emergency Management in Off-Site Area: A Case Study from S City. Advances in Applied Sociology, 7, 181-196. https://doi.org/10.4236/aasoci.2017.75012

Received: April 28, 2017

Accepted: May 20, 2017

Published: May 23, 2017

Copyright ( 92017 by authors and Scientific Research Publishing Inc. This work is licensed under the Creative Commons Attribution International License (CC BY 4.0).

http://creativecommons.org/licenses/by/4.0/

\section{(c) (i) Open Access}

\begin{abstract}
With the development of nuclear power, nuclear power plant safety and emergency management work has aroused great concern of society. Addressing nuclear power plant accidents (NPPAs) overwhelms the capability of single jurisdictional government and spans the boundaries of multiple sectors. However, there is still a lack of research on the antecedent condition, the process mechanism, the basic elements and components of the cross-organization collaboration in the field of NPPAs emergency management in off-site area. On the basis of the initial theory, basic elements and constituent elements of cross-organization collaboration, this article will define the cross-organization collaboration process as a system process interacted with the environment, which consists of four basic elements of collaborative condition, collaborative process, collaborative structure, and collaborative output. Based on the description and analysis of the case of S City, with the explanation of the basic element, the constituent elements and the collaboration mechanism, this article proposes a cross-organization collaboration framework including collaborative antecedents, collaborative process, collaborative structure, collaborative governance and collaborative outcome of NPPAs emergency management in off-site area.
\end{abstract}

\section{Keywords}

Off-Site Emergency Management Cross-Organization Collaboration, Case Study

\section{Introduction}

By 2015, a total of 55 nuclear power plants have been constructed or are being 
operated in Mainland China, and the total installed capacity is over 53.01 million kwh. Nuclear safety is an important guarantee for the development of nuclear energy.

Despite rare breakouts of nuclear power plant accidents (NPPAs), all the occurred accidents worldwide, such as the 1979 Three Mile Island accident in the USA (Mamun, 2013), the 1986 Chernobyl accident in the Soviet Union (Hildegarde, 2016) and the 2011 Fukushima accident in Japan (Masashi, 2016), led to serious property damages and environmental destruction in the surrounding areas.

Obviously, the disastrous situation cannot be controlled by the companies operating the nuclear power plants, and overwhelms capabilities of single jurisdictional government. NPPAs emergency management in off-site area is an emergency operation led by the city's government, cooperated with the enterprise and collaborated with the society, involving complex cooperation and interaction between organizations. How to promote collaboration among the participating multiple emergency management organizations, integrating of units of emergency resources and capacity, is a core problem of NPPAs emergency management in the off-site area.

As an integral part of the overall government theory, collaboration derived from the concept of collaborative governance, is a mainly government governance model which is constituted be horizontal and vertical cross-organizational cooperation and coordination of ideas and actions (Moynihan, 2005). At present, many scholars have researched the framework of cross-organizational collaboration in public management which is focus on normal cross-organizational collaboration, explored the concept and theory of the process of government collaboration and its influencing factors (Provan \& Milward, 2001; Lei, 2015). However, there is a lack of understanding of general antecedent condition, collaborative process, collaborative structure, the outcome and their constituent factors of cross-organizational collaboration in non-normal state.

Based on the theory of cross-organization collaboration, this article identifies the key basic element of cross-organization collaboration framework from the literature, taking the $\mathrm{S}$ city as a case, analyzes its NPPAs emergency management in off-site area from the dimensions of antecedent condition, collaborative process, collaborative structure, and outcome, finally proposes a cross-organization collaboration analysis framework of NPPAs emergency management in offsite area.

\section{Literature Review and Theoretical Background}

\subsection{Cross-Organization Collaboration}

Currently scholars have made many different definitions of cross-organization collaboration, this article mainly uses Bryson's definition (Bryson et al., 2006) and defines cross-organization collaboration as the linking or sharing of information, resources, activities, and capabilities by organizations in two or more sectors to achieve jointly an outcome that could not be achieved by organiza- 
tions in one sector separately.

Cross-organization collaboration is generally driven by different factors. One of the important initial conditions is that addressing the current problems, many interdependent organizations which are stakeholders will develop a collaborative agreement in advance, and implement actions driven by the agreement (Simo \& Bies, 2007). The driving force of cross-organization collaboration is mainly from four aspects, leadership, follow-up incentives, interdependence between organizations and the external environment of uncertainty (Emerson et al., 2012). Among them, the important incentive of the cross-organization collaboration is the key driven factor (Romzek et al., 2012).

There are many factors that influence the process of cross-organization collaboration. The process of developing a collaborative plan requires a deep understanding of the issues that may be encountered in the collaboration, and the development of a corresponding collaboration plan for the target priority sequence (Clarke \& Fuller, 2010). The trust relationship between inter-sectoral organizations constantly plays an important factor in the study of cross-organization collaboration (Lee et al., 2012). Communication among inter-organizations in the process of cross-organization collaboration emphasizes that complex collaborative processes regularly involve compromise and reconstruction, and higher-level command systems are conceptually far different from individual organizations (Koschmann et al., 2012).

The design and reconstruction of organizational structure is an important carrier to achieve cross-organization collaboration. The cross-organization collaboration can have multiple forms in practice, including the vertical collaborative dimension at the cross-sector level in the government, the horizontal collaborative dimension between different functional departments at the same government level, and the horizontal public-private partnerships between government and non-governmental organization (Kapucu, 2009). Cross-organization collaboration simultaneously can be divided into collaboration between government agencies at the government level, collaboration between government and the third sector at the social level, and cross-organizational collaboration among administrative actors at the administrative jurisdiction level (Bryson et al., 2015). The inherent ambiguity and complexity of cross-organization collaboration will lead to dynamic changes in the structure of collaborative organizations, and dynamic changes in collaborative objectives (Vangen \& Huxham, 2012). The cross-organizational structure will be respected by external factors including opportunities for collaboration, public policy, policy areas, system stability, resource availability, and environmental complexity and dynamics (Cornforth et al., 2015).

Cross-organizational collaboration is a comparatively complex process of organizational collaboration. Primarily based on the theory of system dynamics, combined with the organizational theory and the resource dependence theory, cross-organizational collaboration is mainly composed of five basic elements: primitive conditions, formal and informal processes, formal and informal structures, unpredictability and constraints, and output structure and responsibilities 
(Bryson et al., 2006). On the basis of the initial conditions, the collaborative process and the input result, the collaboration process should include the negotiation of face-to-face dialogue, trust establishment, collaborative actions, sharing understanding and making commitments (Ansell \& Gash, 2008). The ideal organizational structure of cross-organization collaboration primarily includes participation in governance, lead organization and network management organization. And he key influencing factors are trust degree, participation quantity, goal consistency, network management requirement and ability level (Provan \& Milward, 2001). In the respective of the system theory, cross-organization collaboration framework composes with driver, collaborative governance system, collaboration mechanism, action, influence and adaptability (Emerson et al., 2012).

The current literature in the field of the cross-organization collaboration have primarily discussed the basic conditions of the cross-organization collaboration, focused on the process of inter-organization collaboration and the organizational structure of collaboration. Scholars have mainly focused on the cross-organization collaboration between normal public policy formulation and normal public problem solving, and explored the organizational structure formed characteristics and types in cross-organization collaboration. However there is still a lack of research on the antecedent condition, the process mechanism, the basic elements and components of the cross-organization collaboration in the field of NPPAs emergency management in off-site area.

\subsection{Theoretical Background}

1) Resource dependence theory

The theory of resource dependence refers to the fact that organizations usually live in a resource-limited environment that requires varying degrees of reliance on the resources of other organizations to survive. The organization's dependence on resources depends primarily on three decisive factors: the importance of resources for the survival of the organization; the extent to which a particular group within or outside a group acquires or processes the use of resources; and the extent to which alternative sources of resources exist (Pfeffer \& Salancik, 1978). One of the important contributions of resource dependence theory is to explain that an organization can rely on another organization, and that the two organizations can also be interdependent. This dependent process of interaction can further demonstrate the power relations and operational structure between organizations, which is being a bridge between the behavior and the structural differences in the connection organization. In this article, the theory of resource dependence proposes a reasonable explanation for collaboration intention.

2) System theory

System theory refers to any system is composed of a number of elements in a certain form of structural structure with a certain organic whole, the system and its elements between the interdependence and interaction of the results will influence the organization's overall function. System is an organic whole, the elements of the system will not exist in isolation, but are in a certain position, play a 
specific role, between the system and the elements of this interdependence and the results of the Will affect the overall function of the organization (Von Bertalanffy, 1968). From the basic approach to system analysis, any organizational system works after a closed-loop relationship between input-to-output-feedback between its environment. This article will build a cross-organization framework of the NPPAs emergency management in off-site area with the system theory that provides an overall system view and a closed-loop principle of input-tooutput between system and environment.

3) Network governance theory

Network governance theory refers to a new public-private sector collaboration governance model, participated with non-profit organizations, profit organizations and other multi-subject to in the provision of public services (Goldsmith \& Eggers, 2005). The theory of network governance is divided into four governance dimensions: First, the multiple organizations governance, including government departments, private sector, non-profit organizations and social citizens; second, the multiple governance mechanism, including the government governance, market governance and social management; third, governance structure network, the government and other social organization are equal to collaborate in the form of service network to achieve public interest which is independent with the government authority. In this article, as the theoretical basis, network governance theory emphasis the multiple organization participation of government, private sector and non-profit organization, which provides a integration way of government governance, market governance and social governance in cross-organization collaboration governance.

\section{The Basic Element of the Cross-Organization Collaboration Framework}

The cross-organization collaboration is a dynamic process of the system. From the development of organizational goals, the various departments in the organization are independent of each other, interrelated and mutually constrained to form a unified body which is the input-transformation-output of the whole process management (Johnson et al., 1963), any organization system forms its input-transformation-output closed-loop relationship by the interaction with its environment. The cross-organization collaboration mechanism follows the input-transformation-output process management. Therefore the cross-organization collaboration process can be divided into system input, transformation and system output three major components. In the part of transformation, collaborative structure is the main carrier to achieve the cross-organization collaboration, dynamic collaboration process is the main form of the cross-organization collaboration. Thus the transformation management process of the cross-organization collaboration is divided into the collaborative process and the collaborative structure.

On the basis of the initial theory, basic elements and constituent elements of cross-organization collaboration, this article will define the cross-organization 
collaboration process as a system process interacted with the environment, which consists of four basic elements of collaborative condition, collaborative process, collaborative structure, and collaborative output. After that, taking the $S$ city as a case, we will describe and analyze the NPPAs emergency management in off-site area from the dimensions of collaborative condition, collaborative process, collaborative structure, and collaborative output.

\section{The NPPAs Emergency Management in Off-Site Area: Taking the $\mathrm{S}$ City as a Case}

\subsection{The Collaborative Condition of the NPPAs Emergency Management in Off-Site Area}

When the nuclear power plant accident emergency management action into the emergency state in off-site area, it means that radioactive material which was released by the nuclear power plant internal accident has exceeded the control of nuclear power base, and influenced the $\mathrm{D}$ area $10 \mathrm{~km}$ smoke plume emergency planning area which is outside the nuclear power base and continued releasing. At this time, the local government must take to a series of off-site emergency management action which including guiding the evacuation of residents, organizing burglary and distributing the medical iodine tablets.

A single off-site emergency management action is often difficult to achieve the desired emergency effect, and even causes secondary derivative disasters. Take the evacuation action as an example, if the $\mathrm{D}$ district government civil affairs department does not cooperate with the delivery department and the traffic police department, even if the $\mathrm{D}$ district civil affairs department has designed the sub-regional evacuation operations in batches, there is no enough vehicles to evacuate dispatch without the cooperation of the transportation department, traffic regulation and road diversion will not be implemented successfully without the cooperation of the traffic police department. As the result, emergency plume area limited road resources will be overused, evacuation vehicles will be blocked, which will trigger even greater social panic.

In the NPPAs off-site emergency management, exclusively a single juristic department or a single government is difficult to deal with. Take resident resettlement as an example, relying on the area D District government emergency power is far from enough. Due to the number of emergency shelters in D District cannot meet the entire smoke plan emergency area transfer residents' resettlement needs, D District government need to cooperate with the nearby L District government and P District government, to collaborate the emergency shelters in L District and P District to resettle the evacuation of the residents.

Emergency information and resources are fragmented in the characteristics of different participating organizations. Set iodine tablets distributing action as an example, iodide resources and the information of the number which is of the residents who is needed to take the iodine tablets, are fragmented in different management departments (Figure 1). Currently iodine tablets of resources are stored in the D District CDC, and the basic information of the jurisdiction residents are 


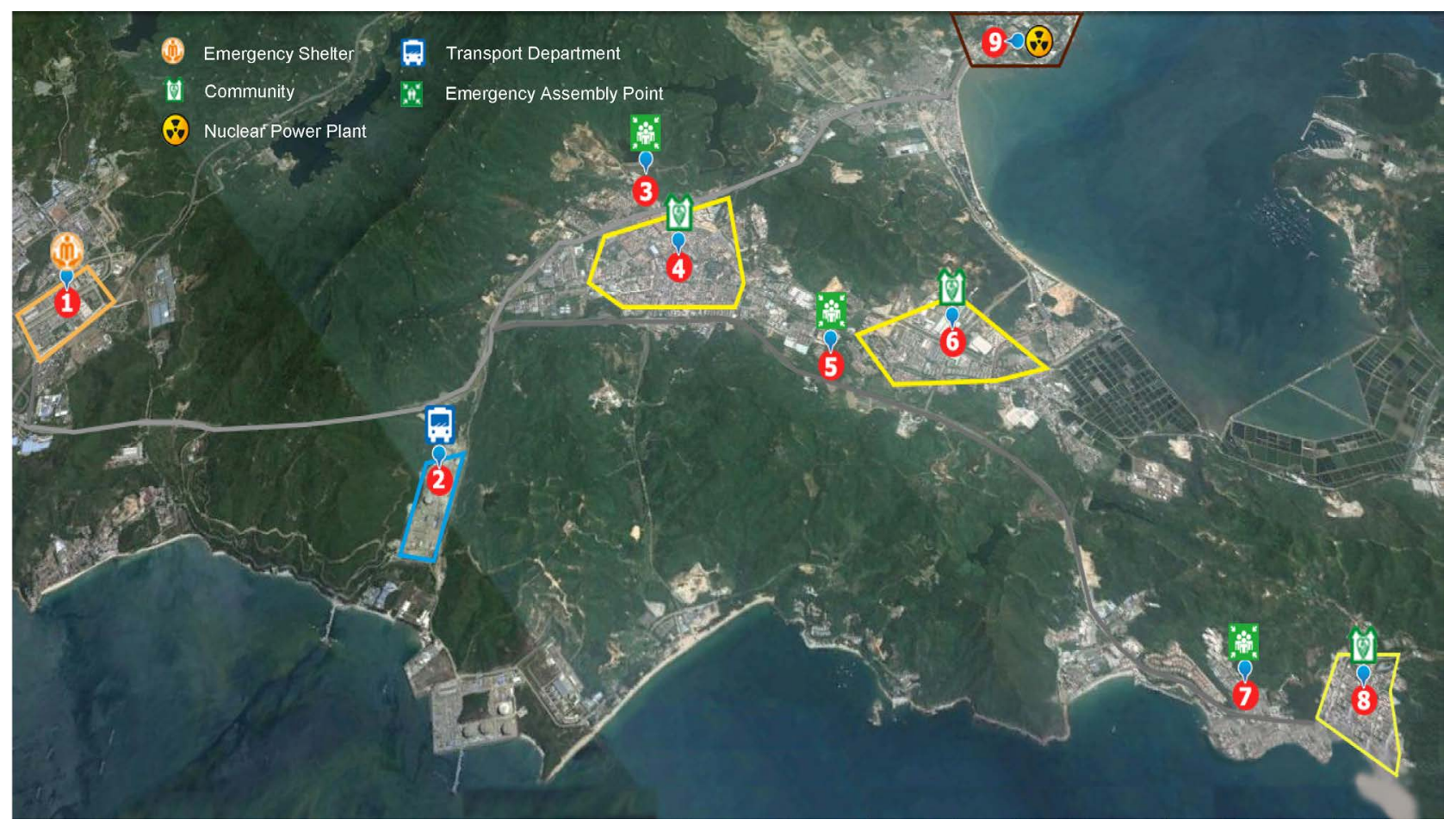

Figure 1. Map of the NPPAs emergency management in off-site area.

collected by the offices of the jurisdiction community. In order to complete the iodine tablets distributing action emergency task, the D District CDC and the offices of the jurisdiction community would share the basic information of the jurisdiction residents and distribute the iodine tablets together with cross-organization collaboration.

\subsection{The Collaborative Process of the NPPAs Emergency Management in Off-Site Area}

1) Emergency leadership

In the off-site NPPAs emergency management, S City Emergency Management Committee (EMC) undertakes the leadership role in cross-organizational emergency collaboration by establishing the S City NPPAs emergency headquarters. As the lead organization in off-site NPPAs emergency management, $\mathrm{S}$ City Emergency Management Committee has overall responsibility for S city NPPAs emergency management work in off-site area. As the daily office of the $S$ City Emergency Management Committee, S City Emergency Management Office has assumed the role of liaison organizations in cross-organization emergency collaboration, which is responsible for communication among the Provincial NPPAs Emergency Command, D District NPPAs Emergency Command Center and Nuclear Power Operation Unit.

The members of the S City Emergency Committee include the municipal government department, the key functional units in the city, as well as the key enterprises that provide basic public services and the nuclear power plant. Thus $\mathrm{S}$ City Emergency Committee is completely able to obtain internal and external 
support and resources, and build up its own recognized authority as the highest command organization in the off-site NPPAs emergency management.

2) Emergency collaborative platform

According to the S City Emergency Preparedness Plan for Nuclear Accident in off-site area, S City NPPAs emergency headquarters establish 13 NPPAs emergency functional group which is responsible for implementing the emergency response actions in off-site area. At the same time, each emergency function group leader should arrive to S City NPPAs emergency headquarters in half an hour to participate in NPPAs emergency management joint command. Therefore S City NPPAs emergency headquarters has become a joint planning and decision-making emergency response platform for off-site NPPAs emergency management.

3) Draft collaborative emergency plan

The collaborative emergency plan of off-site NPPAs emergency management refers to the updated and targeted emergency action plan which is according to the accident situation in real time. The process of drafting collaborative emergency plan is a multi-sectoral joint decision-making action. Not only D District Government provides the important emergency demand information, but also the environmental monitoring organization updates the emergency situation information in a real time, and the logistics organizations supplies the existing emergency resource reserves.

4) The trust in emergency collaboration

Before the implementation of emergency response, different organizations need to identify a common intent of collaborative actions. In the off-site NPPAs emergency management, participated organizations have a common intent of cross-organization collaboration that is to protect the lives and property of the residents in the area and to maintain social security and stability. Information sharing is an important basis for different organizations to achieve emergency collaboration. Participated organizations which need to implement collaborative action can share information through the exchange of information within the emergency function group or in the S City NPPAs emergency headquarters. S City Emergency Committee every two years will hold a joint emergency exercise participated by the involved organizations to find the emergency collaborative process problems, and enhance the practical experience of collaboration.

5) Conflict management of emergency collaborative process

Conflict management of emergency collaborative process primarily reflected in two aspects: on one hand, S City Emergency Committee builds up the S City NPPAs emergency headquarters that is a collaborative decision-making platform which provides an collaborative consultation platform for participated organizations to negotiate the complex problems in off-site NPPAs emergency management; on the other hand, disentitling the organization in charge of the joint decision which owns the final decision-making power in multiple decision-making options and is responsible for the conflict management in emergency collaborative process. 


\subsection{The Collaborative Structure of the NPPAs Emergency Management in Off-Site Area}

1) The evolution of collaborative organizational structure

Emergency response situation is real-time changes, according to the relevant nuclear emergency laws, regulations and emergency plans, nuclear power plant emergency response state is divided into four basic situation: emergency standby, plant emergency, field emergency and off-site emergency, the relevant emergency response levels are four-level response, three-level response, two-level response and one-level response. Different emergency organizations need to be set up for different response levels. The cross-organization collaborative structure in off-site emergency management is characterized by the evolution of the nuclear accident situation, the organizational structure of the organization has been expanding, the division of labor has been refined.

2) Vertical and horizontal integration of cross-organization collaborative network

The vertical organization relationship of cross-organization collaboration in NPPAs off-site emergency management refers to the collaborative relationship based on the traditional bureaucratic system based on the existing superior and lower relations. Participate in the organization through the mandate, command and supervision of the way longitudinal cooperation. According to the organization level, the vertical organization relationship can be divided into the same level of vertical relationship and cross-level vertical relationship.

However, the vertical organization relationship cannot completely meet the needs of emergency collaboration, and easily result to emergency collaborative fragmentation and multi-center. S City Transportation Commission can dispatch emergency traffic resources, $S$ City traffic police brigade can protect the emergency channel flow, the two participating organizations to complement each other's emergency capabilities, and can jointly serve the emergency targets for traffic protection, but at the same level, it is difficult to pass vertical organization relations to collaborate. NPPAs off-site emergency management collaboration which is based on vertical organization collaborative relationship increases the horizontal collaborative relationship, to build the off-site emergency management network. According to the form of horizontal organizational relationship, it can be divided into three categories: communication collaborative relations, decision-making collaborative relation and collaborative relations in emergency process.

3) Collaborative governance

In the NPPAs off-site collaborative emergency management process, S city apply administrative governance, market governance and social governance three governance methods by synthesis for NPPAs off-site collaborative emergency management. First, administrative governance is the primary mode of collaborative governance. As the emergency information and resources are mainly in the hands of the government, based on the professional management of off-site emergency management, on the basis of the S City Emergency Com- 
mittee S City Government establishes the S City NPPAs emergency headquarters. The S City municipal government emergency departments mainly use the bureaucratic administrative collaborative mode, by setting up emergency functional groups, to cooperate in the implementation of specific off-site emergency management measures. Second, market governance is an auxiliary collaborative governance tool. In order to improve the efficiency of emergency allocation of resources, by having signed an emergency supplies supply agreement with enterprises, paid emergency recruitment with logistic enterprises for vehicle resources, S City has taken advantage of market mechanisms to ensure emergency response resources needs. Third, social governance is a powerful complement to collaborative governance. In the NPPAs off-site collaborative emergency management process, the community volunteer service team has collaborated with the S City Public Security Bureau and S City Armed Police Force to maintain the social order, search and rescue and help the community special people.

\subsection{The Collaborative Outcome of the NPPAs Emergency Management in Off-Site Area}

In the NPPAs off-site collaborative emergency management, the primary outcome is to achieve the established emergency goals that fulfilling the functions of the government to maintain social security and the safety of people's lives and property and to reduce the loss and destruction of life, property and the environment caused by the proliferation of radioactive material. On the basis of the collaborative goal achieving, the emergency departments have performed their respective departments of the emergency mission and responsibilities to achieve the individual intent of the department. Successful experience in cross-organization collaboration will change the existing organizational structure, such as formal collaboration agreements that will be made by the less connective organizations. The new collaborative mechanism will lead to the birth of new participating organizations, so as to improve the existing cross-organization collaboration network of off-site emergency management, and may bring to the public a new off-site emergency concept.

China has not really appeared a large area of radioactive material proliferation of serious nuclear accident, based by the emergency plans and regulations of the NPPAs collaborative emergency management in off-site area, the institution system of the NPPAs collaborative emergency management in off-site area clearly stipulates the emergency responsibilities of the government departments and relevant institutions. An off-site emergency management of cross-organization collaboration can be the previous plan system in the different emergency departments of the duties of inspection and reflection, to further amend the duties of improper, clear vague duties.

\section{A Cross-Organization Collaboration Framework of the NPPAs Emergency Management in Off-Site Area}

In depth analysis of the S City NPPAs cross-organization collaborative emer- 
gency management process, according to the theory of network governance, on the basis of the four dimensions of collaborative antecedents, collaborative process, collaborative structure, and collaborative output, this article increases the collaborative governance as the fifth main element, and identities the formations of the main elements, finally proposes a cross-organization collaboration framework of the NPPAs emergency management in off-site area.

\subsection{Collaborative Antecedents}

1) The risk of secondary disasters resulted by a single emergency action

Faced with complex disasters, a single action of the NPPAs emergency management in off-site area are frequently difficult to achieve the desired emergency effect, and even result in secondary derivative disasters. Thus, the risk of a secondary disasters resulted by a single emergency action is to drive the cross-organization collaboration among different off-site emergency management departments.

2) The inadequate emergency capability of single department

The current unconventional disasters are characterized by precursory concealment, complex evolution and secondary derivative disasters, due to separation of departmental interests by bureaucracy separation, interest segmentation and official "broker" orientation, and the subdivided reform of the government bureaucracy system makes the inadequate ability of functional departments. Therefore the inadequate emergency capability of single department has driven to collaborate among different governments at horizontal level and different department at vertical level in off-site emergency management of the NPPAs.

3) The fragmentation of emergency information and resource

Based on the fragmentation of emergency information and resource, interrelated departments have to operate the collaborative actions to achieve the maintenance of the area residents of life and property safety and social security and stability of the government public duties.

\subsection{Collaborative Process}

1) Establish the emergency command system

Cross-organization collaboration constantly requires the leading organization to schedule different organizational resources by integrating formal and informal organizations. Thus the local government needs to rapidly establish the emergency command system in limited time, determine the leadership, build up the emergency functional groups to set up an cross-organization collaboration emergency platform.

2) Guarantee the authority of collaborative command

In order to ensure the leading organization of the collaborative emergency command system own the rights of scheduling different organizational resources and integrating different organizations, the leading organization need to be granted the collaborative command legality by guarantying the authority of collaborative command. The collaborative command legality of the leading organi- 
zation is originated mainly from the following aspects: the capability to obtain internal and external support and resources, can be recognized for internal and external participants, and communication which is a high degree of trust cooperation between the various organizations.

3) Enhance the trust of emergency collaboration

Trust is the logical starting point for emergency collaboration between different participating organizations and the basis of cross-organization collaboration. First participated organizations need to has an effective common emergency goals, then followed by different ways to form a positive interaction to achieve the sharing of information and knowledge, and finally to fully demonstrate the capability of mutual response to understand the status in the cross-organization collaboration, so that enhancing the trust of collaboration.

4) Manage the conflict in the collaborative process

There are potential conflicts between different participating organizations due to differences in the field of knowledge and emergency response experience in cross-organization collaboration. To manage conflicts in emergency collaboration by providing a collaborative decision-making platform for collaborative consultations and determining responsible organization in collaborative decision-making.

\subsection{Collaborative Structure}

1) The dynamic collaborative structure by the dynamic emergency situation

The key of emergency collaboration is capable to take effective emergency strategy by the change of organizational environment. On the basis of the dynamic characteristics of emergency situation, collaborative structure will be dynamic based on the needs of response, and with the changes in the emergency situation evolved.

2) Vertical organization relationship is the basis of collaborative structure

The cross-organization collaboration of NPPAs emergency management in off-site area is led by the government, participated with social forces. Thus the vertical organization relationship which includes mandate, command and supervision has become the basis of collaborative structure.

3) Horizontal organization relationship is the complementarity of collaborative structure

In order to solve the problem of fragmentation and multi-centering caused by vertical organization relations, the horizontal organization relationship which includes Information exchange and sharing, resource sharing, joint decision-making and planning, emergency collaboration and action coordination among participated organizations is the complementarity of collaborative structure.

\subsection{Collaborative Governance}

1) Administrative governance is the main way of collaborative governance

According vertical organization relationship is the basis of collaborative struc- 
ture, the organizations participated in the cross-organization collaboration of NPPAs emergency management in off-site area have adopted administrative governance as the main way of collaborative governance.

2) Market governance is an auxiliary tool for collaborative governance

The organizations participated in the cross-organization collaboration of NPPAs emergency management have primarily used the market tools of signing emergency cooperation agreement and emergency expropriation compensation to meet the emergency needs of cross-organization collaboration and improve the allocation of emergency resources efficiency.

3) Social governance is a powerful complement to collaborative governance

Through the development of social forces to respond to the ability to guide the participation of multiple social forces, social governance will be used as a powerful complement to collaborative governance in the cross-organization collaboration of NPPAs emergency management in off-site area.

\subsection{Collaborative Outcome}

1) Achieve the overall emergency intent

The cross-organization collaboration of NPPAs emergency management in off-site area is aimed to achieve the overall emergency intent which is the performance of the government to maintain social security and people's lives and property functions

2) Complete the individual emergency mission

As the different participating individuals have the responsibility of fulfilling the emergency management department, the emergency task assigned by the higher-level organization and the emergency mission of defending the individual's emergency benefit. On the basis of realizing the overall emergency target, the participating individuals participating in the emergency cooperation have completed their own individual emergency mission.

3) Enhance the tightness of the collaborative network

Cross-organization collaboration can increase the trust between participating organizations, closely participate in the relationship between organizations, and help to form a new emergency cooperation mechanism, and enhance the tightness of the collaborative network.

4) Clarify the responsibilities of the collaborative organization

Through the cross-organization collaboration of NPPAs emergency management in off-site area, we can use the result of emergency collaboration to re-evaluate and analyze the responsibilities of emergency response organizations and clarify the responsibilities of participating organizations.

\subsection{The Cross-Organization Collaboration Framework}

Based on the description and analysis of the case of S City, with the explanation of the basic element, the constituent elements and the collaboration mechanism, this article proposes a cross-organization collaboration framework of NPPAs emergency management in off-site area (Figure 2). 


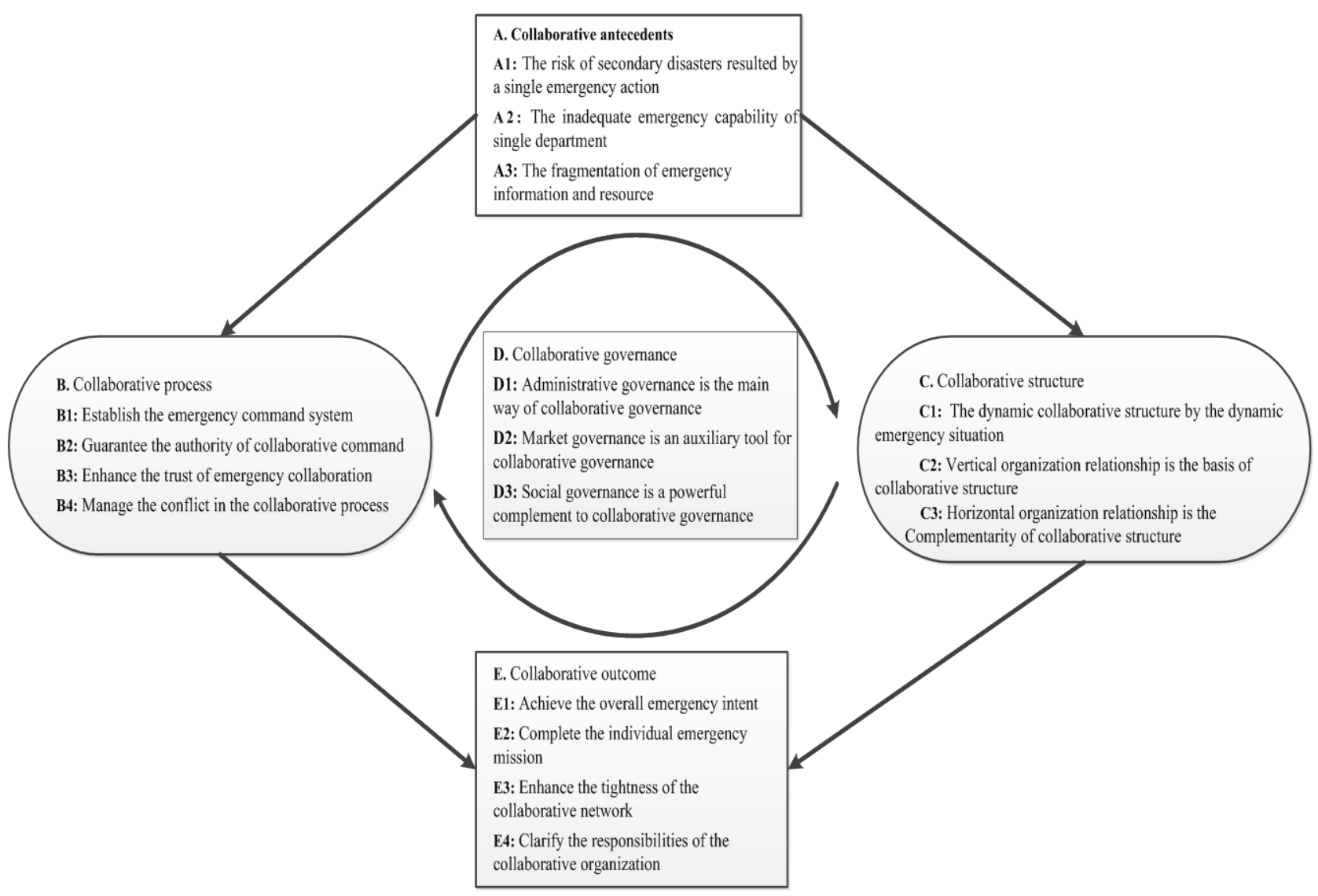

Figure 2. Map of a cross-organization collaboration framework of NPPAs emergency management in off-site area.

First of all, the risk of secondary disasters resulted by a single emergency action, the inadequate emergency capability of single department and the fragmentation of emergency information and resource are the collaborative antecedents.

Secondly, we need to establish the emergency command system, guarantee the authority of collaborative command, enhance the trust of emergency collaboration and manage the conflict in the collaborative process in the collaborative process.

Thirdly, the collaborative structure will evolve with the dynamic emergency situation. Vertical organization relationship is the basis of collaborative structure, and horizontal organization relationship is the complementarity of collaborative structure.

Fourthly, Administrative governance is the main way of collaborative governance, market governance is an auxiliary tool, and social governance is a powerful complement.

Finally, the collaborative outcome is to achieve the overall emergency intent, complete the individual emergency mission, enhance the tightness of the collaborative network, and clarify the responsibilities of the collaborative organization.

\section{Conclusion}

Based on the case of S City, this article defines the cross-organization collabora- 
tion process of NPPAs emergency management in off-site area as a system process interacted with the environment, which consists of four basic elements of collaborative condition, collaborative process, collaborative structure, and collaborative output. After that, taking the $S$ city as a case, this article has described and analyzed the NPPAs emergency management in off-site area from the four dimensions. In depth analysis of the S City NPPAs cross-organization collaborative emergency management process, according to the theory of network governance, this article proposes a cross-organization collaboration framework of NPPAs emergency management in off-site area and its main element which explains collaborative antecedents, collaborative process, collaborative structure, collaborative governance, and collaborative output. And there is a certain logical relationship between the different elements, with the change of emergency response to the cycle of interaction. This cross-organization collaboration framework analyzes the cross-organization collaboration mechanism of NPPAs emergency management in off-site area, which provides an analytical way for scientific explanation of cross-organization collaboration phenomenon. Ultimately, in the process of practical management practice, the cross-organization collaboration framework of NPPAs emergency management in off-site area will be affected by various factors. The framework is only preliminary and needs further investigation and improvement.

\section{References}

Ansell, C., \& Gash, A. (2008). Collaborative Governance in theory and Practice. Journal of Public Administration Research and Theory, 18, 543-571. https://doi.org/10.1093/jopart/mum032

Bryson, J. M., Crosby, B. C., \& Stone, M. M. (2006). The Design and Implementation of Cross-Sector Collaboration: Propositions from the Literature. Public Administration Review, 66, 44-55. https://doi.org/10.1111/j.1540-6210.2006.00665.x

Bryson, J. M., Crosby, B. C., \& Stone, M. M. (2015). Designing and Implementing Cross-Sector Collaborations: Needed and Challenging. Public Administration Review, 75, 647-663. https://doi.org/10.1111/puar.12432

Clarke, A., \& Fuller, M. (2010). Collaborative Strategic Management: Strategy Formulation and Implementation by Multi-Organizational Cross-Sector Social Partnerships. Journal of Business Ethics, 94, 85-101. https://doi.org/10.1007/s10551-011-0781-5

Cornforth, C., Hayes, J. P., \& Vangen, S. (2015). Nonprofit-Public Collaborations: Understanding Governance Dynamics. Nonprofit and Voluntary Sector Quarterly, 44, 775-795. https://doi.org/10.1177/0899764014532836

Emerson, K., Nabatchi, T., \& Balogh, S. (2012). An Integrative Framework for Collaborative Governance. Journal of Public Administration Research \& Theory, 22, 1-29. https://doi.org/10.1093/jopart/mur011

Goldsmith, S., \& Eggers, W. D. (2005). Governing by Network: The New Shape of the Public Sector. Brookings Institution Press and the Innovations in American Government Program at the John F. Kennedy School of Government at Harvard University.

Johnson, R. A., Kast, F. E., \& Rosenzweig, J. E. (1963). The Theory and Management of Systems. Journal of the American Statistical Association, 58, 870. https://doi.org/10.2307/2282763

Kapucu, N. (2009). Interorganizational Coordination in Complex Environments of Dis- 
asters: The Evolution of Intergovernmental Disaster Response System. Journal of Homeland Security and Emergency Management, 6, Article 47.

https://doi.org/10.2202/1547-7355.1498

Koschmann, M. A., Kuhn, T. R., \& Pfarrer, M. D. (2012). A Communicative Framework of Value in Cross-Sector Partnerships. Academy of Management Review, 37, 332-354. https://doi.org/10.5465/amr.2010.0314

Lee, H.-W., Robertson, P. J., Lewis, L., Sloane, D., Galloway-Gilliam, L., \& Nomachi, J. (2012). Trust in a Cross-Sectoral Interorganizational Network. Nonprofit and Voluntary Sector Quarterly, 41, 609-631. https://doi.org/10.1177/0899764011414435

Lei, Y. D., Liu, C. C., Zhang, L. B. et al. (2015). Adaptive Governance to Typhoon Disasters for Coastal Sustainability: A Case Study in Guangdong, China. Environmental Science \& Policy, 54, 281-286.

Mamun, M. A. (2013). Recent Fukushima Nuclear Detonation, Chernobyl Nuclear Fallout, Three Mile Island Nuclear Accident and Atomic Bomb Explosion-Rethinking the Effects of Nuclear Radiations over Human Health. International Journal of Radiation Research, 11, 63-80.

Moynihan, D. P., \& La, R. M. (2005). Leveraging Collaborative Networks in Infrequent Emergency Situations. Washington DC: IBM Center for the Business of Government.

Pfeffer, J., \& Salancik, G. R. (1978). The External Control Organizations: A Resource Dependence Perspective. New York: Harper \& Row.

Provan, K. G., \& Milward, H. B. (2001). Do Networks Really Work? A Framework for Evaluating Public-Sector Organizational Networks. Public Administration Review, 61, 414-423. https://doi.org/10.1111/0033-3352.00045

Romzek, B. S., LeRoux, K., \& Blackmar, J. M. (2012). A Preliminary theory of Informal Accountability among Network Organizational Actors. Public Administration Review, 72, 442-453. https://doi.org/10.1111/j.1540-6210.2011.02547.x

Simo, G., \& Bies, A. L. (2007). The Role of Nonprofits in Disaster Response: An Expanded Model of Cross-Sector Collaboration. Public Administration Review, 67, 125-142. https://doi.org/10.1111/j.1540-6210.2007.00821.x

Vangen, S., \& Huxham, C. (2012). The Tangled Web: Unraveling the Principle of Common Goals in Collaborations. Public Administration Research and Theory, 22, 731-760. https://doi.org/10.1093/jopart/mur065

Von Bertalanffy, L. (1968). General System Theory: Foundations, Development. New York: George Braziller. 
Submit or recommend next manuscript to SCIRP and we will provide best service for you:

Accepting pre-submission inquiries through Email, Facebook, LinkedIn, Twitter, etc. A wide selection of journals (inclusive of 9 subjects, more than 200 journals)

Providing 24-hour high-quality service

User-friendly online submission system

Fair and swift peer-review system

Efficient typesetting and proofreading procedure

Display of the result of downloads and visits, as well as the number of cited articles Maximum dissemination of your research work

Submit your manuscript at: http://papersubmission.scirp.org/

Or contact aasoci@scirp.org 